\title{
A Sociedade Portuguesa de Química em tempo de mudança
}

De 6 a 11 de Abril do corrente ano realizar-se-á no Porto o X Encontro Anual da SPQ, altura em que se comemorarão solenemente as bodas de diamante da nossa Sociedade. A escolha da cidade do Porto para a realização deste Encontro (quebrando, assim, a rotatividade habitual que o levaria à região sul) faz-nos voltar ao local da Fundação da Sociedade Chimica Portuguesa. Durante o X Encontro realizar-se-á uma Assembleia Geral da SPQ * onde serão eleitos os novos corpos directivos nacionais (Secretário-Geral, Secretários-Gerais Adjuntos, Tesoureiro, Mesa da Assembleia Geral e Conselho Fiscal).

O $10 .^{\circ}$ Encontro, em 1987, marcará o fim de uma época da vida da SPQ, pós 1974, que foi essencialmente uma época de relançamento e durante a qual se criaram também algumas rotinas de funcionamento. Simbólico talvez do fim de um período ainda mais alargado da história da SPQ foi o falecimento, em Novembro de 1986, de Herculano de Carvalho, figura importante no passado da Sociedade e que, até à morte, continuou a ser o Director da Revista Portuguesa de Química.

1987 tem de ser o tempo de mudança: ou se injecta novo sngue e nova dinâmica na vida da Sociedade ou então as rotinas que começaram por ser saudáveis transformar-se-ão em rotinas rotineiras e a SPQ caminhará para um novo estiolamento.

É principalmente isto que torna o X Encontro e as eleiçôes que então se vão realizar tão importantes para a Vida da Sociedade. Impõe-se, pois, a todos nós, sócios da SPQ, que façamos uma reflexão sobre o futuro que desejamos para a nossa Sociedade e que participemos maciçamente nas decisões que podem influenciar esse futuro.

Como a estratégia para a construção do futuro assenta, naturalmente, no conhecimento do passado e do presente parece-me oportuno relembrar aos colegas, em breve balanço e, na minha visão, o que foi a história recente da SPQ e à qual estive intimamente ligado. Estas breves notas não pretendem, de forma alguma, ocupar o espaço de uma História da nossa Sociedade, tarefa que se impð̃e mas que até hoje descurámos.

O Boletim da SPQ foi a primeira manifestação dirigida a todos os sócios que mostrou que a sociedade voltava a estar activa. O ponto da situação foi feito no Editorial do $1 .^{\circ}$ número, publicado há quase dez anos, em Junho de 1977, sob a direcção da Ana M. Lobo: «Em Fevereiro de 1974 foi criada a Sociedade Portuguesa de Física tendo ficado a Sociedade Portuguesa de Química como continuadora da antiga Sociedade Portuguesa de Química e Física. Por razðes várias a Sociedade Portuguesa de Química teve um longo período de estagnação. Recentemente, entre um grupo de pessoas mais ligadas à Sociedade Portuguesa de Química, surgiu o impulso de relançar a Sociedade. Estas pessoas organizaram-se em Comissão ad hoc $e$ em Julho de 1975 foi eleita, em Assembleia Geral, uma Comissão Instaladora constituída por: Jorge Calado (IST), Romão Dias (IST), Cardoso Pereira (FCUL), Silveira Ramos (FCUL), J.C.R. Reis (FCUL) e César A.N. Viana (FCUL).

As tarefas cometidas a esta Comissão foram, numa fase de arranque, assegurar as condiçōes minimas de funcionamento, tentar dinamizar a Sociedade à escala nacional e programar, a curto prazo, algumas realizaçoes que criem uma base concreta para a vida da Sociedade.

Uma das primeiras preocupaçōes desta Comissão foi conseguir uma sede própria independente e dotada de serviços administrativos adequados. Em seguimento a conversações havidas com o Instituto de Alta Cultura foi possível concretizar este anseio graças à concessão de um subsídio especial que permitiu o aluguer de um andar (...) para a instalação da nossa Sociedade em conjunto com outras Sociedades congéneres (...)m.

Também naquele $1 .^{\circ}$ número do Boletim se dá conta da situação da Revista Portuguesa de Química:

"Como é do conhecimento dos sócios também a publicação da Revista Portuguesa de Química sofreu grande interrupção mas julgamos ter ultrapassado as dificuldades e estamos, neste momento, a preparar a publicação dos números atrasados e relativos aos volumes 16 (de 1974) a 19 (de 1977). Nomeadamente os dois primeiros números do volume 16 já foram recebidos do impressor e estão prontos a serem distribuídos.”

A situação em relação ao pagamento das quotas também é aí referida:

«Dado que nos últimos anos não têm sido recebidas quotas, o pagamento da quota de 1977 só dará direito a receber os números da Revista correspondentes ao volume 19.

Se estiver interessado em receber o volume relativo a 1974 agradecemos que nos envie, além da quota para o pagamento de 1977, a quantia referente à quota do ano de 1974."

Para além de arranjar uma sede nacional, lançar um boletim, tentar pôr a Revista em dia e angariar novos sócios, a Comissão Instaladora. procurou também cumprir o seu mandato organizando realizações que criassem uma base concreta para a vida da Sociedade. E entendeu que essa "base concreta" só poderia ser conseguida através da divulgação e promoção da investigação em Química realizada em Portugal. Assim, em 16 de Dezembro de 1976, realizou-se, no Complexo Inter-

\footnotetext{
- Secretário-Geral da SPQ (1978-1987).
}

- Ver anúncio na pág. 48 
disciplinar, um encontro sobre Química Orgânica e em 5 de Maio de 1977, também no anfiteatro do Complexo Interdisciplinar, realizou-se um encontro de âmbito nacional sobre Química Inorgânica. O sucesso verificado com estes dois encontros sectoriais deu coragem à Comissão Instaladora e a outros sócios que entretanto foram co-optados, nomeadamente M.A.V. Ribeiro da Silva e J.A. Martinho Simøes, para organizarem, agora já em moldes muito mais alargados, o I Encontro Nacional de Química, que teve lugar na Fundação Calouste Gulbenkian, em Lisboa, de 4 a 6 de Janeiro de 1978.

Durante este primeiro Encontro teve também lugar uma Assembleia Geral da SPQ em que foram eleitos os órgãos directivos nacionais da Sociedade segundo os novos estatutos, recentemente aprovados em AG.

Iniciou-se aqui, o que poderemos designar, por analogia, como o periodo constitucional da Sociedade Portuguesa de Química no pós 25 de Abril. Foi então que passei a ocupar o cargo de Secretário-Geral da SPQ, cargo para o qual fui reeleito duas vezes e que em menos de um mês abandonarei. É este período constitucional que agora passarei a descrever de acordo com as grandes áreas de actuação.

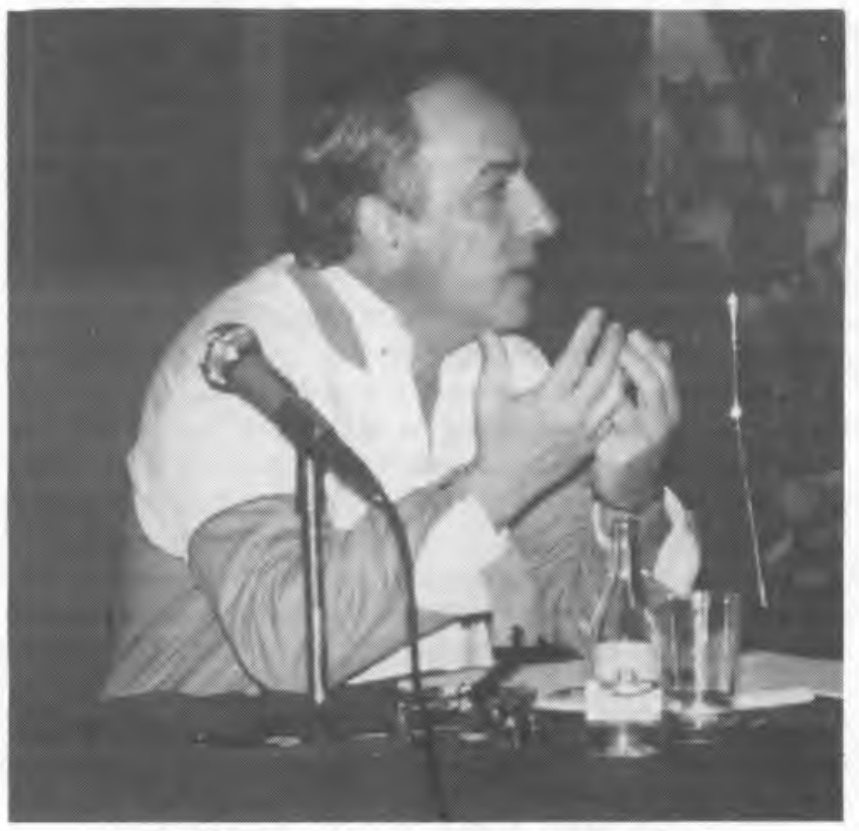

A. Romão Dias, Secretário-Geral da S.P.Q.

\section{Encontros anuais}

O primeiro Encontro Nacional foi um sucesso inesperado. Sucesso pelo número-de participantes e de comunicaçð̃es, pelo nível destas e, sobretudo, pelo ambiente de convívio excepcional que então se criou entre os químicos portugueses. Suspeito que neste encontro se verificou um conhecimento mútuo entre químicos nacionais superior ao existente nas duas décadas precedentes. E surgiu logo a ideia de passar a realizar todos os anos um encontro de âmbito geral e a nível nacional.

Foram muitos os que não acreditaram que fosse possivel manter a regularidade anual para os Encontros, Mas estavam enganados como o prova o facto de em 1987 irmos realizar o Décimo Encontro!

Para além de revelar uma certa regularidade na produção científica nacional na área da Química, a que rapidamente se juntou também a contribuição trazida pelos nossos colegas espanhóis, a realização anual dos Encontros demonstrou uma excepcional dedicação e espírito de sacrifício por parte dos colegas que nas várias universidades, tiveram todo o trabalho inerente à concretização destes encontros. A comunidade química nacional deve sentir-se grata para com estes colegas.

$\mathrm{O}$ nível de atendimento e a qualidade científica dos Encontros tem-se mantido embora com algumas oscilaçōes. Penso, porém, que o balanço global foi extremamente positivo. Por outro lado não posso deixar de fazer aqui as seguintes reflexðes:

- Embora o número de comunicações não tenha diminuído significativamente perdeu-se, nos últimos anos, um pouco o espírito de convívio (muitos colegas só comparecem no dia em que vão afixar o "poster» e depois desaparecem) e sobretudo, o ambiente de festa colectiva da comunidade química nacional que era um dos aspectos mais positivos destes Encontros. Será que as pessoas já se conhecem bem demais? Será que os Encontros são muito longos? Será que a periodicidade anual se está a revelar cansativa? Penso que a próxima direcção da SPQ deve reflectir seriamente sobre este aspecto e fazer um inquérito junto dos sócios para orientação futura.

- A participação de químicos da indústria foi sempre muito reduzida (reflectindo também o que se passa ao nível dos sócios), apesar de todas as tentativas feitas para os aliciar. Se parte da culpa se pode encontrar na falta de imaginação da direç̧ão da SPQ e na eventual falta de interesse prático imediato da investigação em Química realizada em Portugal, a outra parte da culpa reside certamente na estrutura e na natureza da nossa indústria química, dependente tecnologicamente e com um peso relativamente pequeno da química fina. Contribuir para influenciar uma inflexão na natureza da indústria química em Portugal é, certamente, uma obrigação da SPQ. Tentámos e falhámos. Desejamos melhor sorte aos nossos sucessores. É uma tarefa de importância decisiva a nível nacional.

- Em todos os encontros mantivemos uma componente dedicada ao problema do ensino e da aprendizagem da Química, como aliás, era nosso dever. Este aspecto é tão importante que a ele me referirei separadamente mais adiante. Nesta altura queria apenas referir que foram tentados vários modelos: parte científica e parte educacional simultâneas, sequenciais, separadas no tempo e/ou no local. Embora, pessoalmente, seja adepto da fórmula sequencial (como vai voltar a ser adoptado no $\mathrm{X}$ Encontro) devo confessar que não tenho a certeza sobre qual dos modelos serve melhor os objectivos dos Encontros. Talvez esta seja outra área em que a próxima direcção deva fazer um inquérito aos sócios.

\section{Encontros sectoriais e de divisão}

Este foi um campo em que a dinâmica da SPQ nos últimos dez anos foi nitidamente insuficiente. Não rejeito as culpas que me possam caber pessoalmente mas creio que há outros factores a ter em consideração e que reflectem um pouco da natureza da nossa comunidade científica:

- A sua aparente falta de iniciativa e de capacidade organizativa. E digo aparente porque quando se trata de organizar reuniðes no âmbito das organizaçð̌es internacionais (NATO, IUPAC, p.e.) em que o dinheiro é «fácil» e em que o prestígio para o indivíduo que a organiza é elevado, não faltam voluntários. Não tenho 
nada contra este tipo de reuniðes, antes pelo contrário. Gostaria, porém, de ver também todo esse fervor organizativo aplicado na organização de um encontro sectorial no âmbito da SPQ; não direi que dá mais trabalho, mas certamente que não contribui tanto para o desenvolvimento da rede de contactos internacionais do organizador. Contribuiria, porém, bastante para a conjugação de esforços e para a promoção da Química que é feita em Portugal.

- A sua pequena dimensão. O que por si só não é desculpa pois aquela foi várias vezes ultrapassada através de "joint-ventures» com os nossos colegas espanhóis e até com estes e com os franceses.

- A continuada dependência face aos grupos estrangeiros. Se há muitas razð̄es para que isto aconteça talvez seja embaraçoso perguntar porque é que não começa a deixar de ser assim.

Mas, apesar de tudo, alguma coisa foi feita. Para além do Encontro Internacional de Educação em Química, em 1978 (a que me referirei adiante) são de mencionar: O encontro sobre Dinâmica Molecular realizado em Coimbra em 1982, a participação nos encontros sobre Termodinâmica das soluçōes de não-electrólitos («joint-venture» da SPQ e das Sociedades de Química Espanhola e Francesa) e os recentes encontros Luso-Galaicos de Química organizados pela região Norte em colaboração com os nossos colegas da Galiza.

O leitor poderá pensar que o espaço dedicado nestas notas ao problema dos Encontros sectoriais é despropositadamente exagerado. Não é essa a minha opinião. Creio que esses Encontros são extremamente importantes, não só porque a sua existência víria aliviar grandemente os Encontros gerais anuais, tornando-os mais curtos e reforçando-lhes a componente de convívio generalizado, mas também e principalmente porque a sua realização regular seria uma demonstração da maturidade científica da nossa comunidade química.

A história das Divisões segue de perto, e ainda mais probremente, a historia dos Encontros Sectoriais. Exceptuando a Divisão de Educação (que, pelo menos regionalmente, funcionou embora não tenha vingado claramente a nível nacional) e o recente embrião de uma Divisão de Espectrometria de Massa, foi impossível criar Divisð̃es. nem sequer em Química Analítica!

\section{Educação em Química}

A profunda ligação entre a "saúde» da actividade química em Portugal e o ensino desta disciplina aos vários níveis foi, desde o início, um pressuposto da nossa actividade.

Assim no I Encontro Nacional, realizado em Janeiro de 1978 , foi reservada uma tarde ao debate de temas educacionais. Esta experiência revelou duas coisas; por um lado, o enorme interesse que este tema despertava e, por outro, a forma extremamente amadorista e quase que emocional como o tema era abordado. Isto levou a direcção da SPQ a organizar, logo em Outubro do mesmo ano, um Encontro Internacional sóbre a Educação em Química, realizado no LNEC, com a participação de vários especialistas europeus. $\mathrm{Na}$ origem deste encontro esteve o contacto entretanto estabelecido com Malcolm Frazer, então Professor de Educação em Química na Universidade de East Anglia, que sugeriu a realização em Portugal (a coincidir com o Encontro) de uma reunião do grupo de trabalho sobre Educação em Química da FECS (Federação Europeia de Sociedades de Química), associação à qual a SPQ então aderiu.
Com este Encontro Internacional iniciou-se uma nova abordagem, mais profissional e mais "cientifica" da actividade da SPQ na área da Educação, abordagem essa que se veio a reflectir sobre a estrutura da componente educacional de todos os encontros nacionais subsequentes.

Em 1978, na altura da realização do I Encontro haveria em Portugal talvez menos de meia dúzia de doutorados em Educação; hoje esse número atinge quase as três dezenas, sendo alguns deles doutorados em Educação em Quimica. Sem querer, de forma algu$\mathrm{ma}$, reivindicar louros que lhe não são devidos, a SPQ não pode deixar, porém, de ter a sensação de ter contribuído um pouco para o avanço verificado nesta área.

Para além do nível elevado que procurou imprimir à componente educacional dos Encontros Nacionais, foram também outras as iniciativas através das quais a SPQ tentou, com maior ou menor sucesso, melhorar a qualidade do ensino de Química em Portugal e aumentar o interesse por esta disciplina. De entre as muitas iniciativas levadas a cabo são de salientar:

- As Olimpiadas da Química, dedicadas aos alunos dos anos mais avançados do ensino secundário. Esta é uma iniciativa que deveria continuar a ser acarinhada e imaginativamente desenvolvida; o sucesso que teve e o potencial que encerra justificam-no perfeitamente. $\mathrm{O}$ ideal seria a SPQ poder contar com um professor, praticamente a tempo inteiro, só para tratar das Olimpíadas.

- A realização, principalmente na região Norte (com destaque para as famosas experiências de salão) e na região Centro, de várias acçōes de actualização dos professores.

- A publicação, quer a nível nacional quer a nível regional de vários textos dedicados essencialmente aos professores do ensino secundário (ver actividade editorial).

- A publicação de uma pequena brochura (acompanhada por uma colecção de acetatos e de slides) sobre reacçð̄es ácido-base.

Antes de 1974 eram pouquíssimos os professores do ensino secundário sócios da SPQ; hoje constituem metade dos cerca de 2300 sócios. Os conhecimentos mínimos de Química que todo o cidadão (que não seja químico) deve possuir resultam essencialmente da aprendizagem adquirida no ensino secudário. Os conhecimentos de Química que os alunos têm quando entram no terciário para tirar cursos nesta área, e a motivação dos melhores alunos para seguirem carreiras ligadas à Química, resultam também do ensino que for ministrado no secundário. Todas estas razð̃es são sobejamente fortes para que a SPQ continue a dedicar o melhor da sua atenção ao ensino da Química no secundário e aos seus professores. o que não implica, antes pelo contrário, que não se presta igualmente atenção ao ensino da Química no terciário.

\section{Publicações}

A actividade editorial é uma das tarefas principais de qualquer sociedade cientifica. Embora com muitas dificuldades a SPQ também tem procurado cumprir essa tarefa.

\section{A Revista Portuguesa de Química}

Como já referimos, quando a primeira direcção eleita da SPQ do pós 25 de Abril tomou posse, a Revista Portuguesa de Química estava extremamente atrasada. 
Os subsídios da indústria e os anúncios que asseguravam a viabilidade financeira da Revista tinham desaparecido e as dívidas na tipografia tinham parado a publicação. Foi graças ao apoio concedido pelo INIC (que neste momento assegura integralmente os custos de produção embora não os de distribuição) e à grande dedicação de Carlos Pulido e, principalmente de Luís Vilas Boas que foi possivel voltar a levar a Revista a um ritmo praticamente normal de publicação. A recente mudança de Editores e de tipografia conduziu a alguns atrasos, talvez inevitáveis nestas condiçðes.

Independentemente das dificuldades financeiras e dos eternos problemas com as tipografias existe toda uma outra problemática associada com a RPQ. A Revista é distribuída gratuitamente a todos os sócios embora exista a consciência de que são poucos os que efectivamente a lêem. Dada a muito pequena dimensão do nosso meio científico, abandonar a distribuição geral e gratuita e passar para um sistema de assinaturas seria, provavelmente, condená-la à morte. $\mathrm{E}$ há razóes para manter a RPQ: é uma questão de dignidade nacional e é o respeito por uma iniciativa que antecedeu a própria criação da Sociedade.

É preciso atrair artigos de bom nível para a Revista. E isto só será possível se a Revista tiver uma boa divulgação internacional. Porque a comunidade química dos países de expressão portuguesa é muito reduzida, a recente decisão de publicar todos os artigos em lingua inglesa (internacionalmente aceite como a lingua franca da ciência) parece-me acertada. E a RPQ continua a ser referenciada pelo Chemical Abstracts, o que é bom. Só é pena que tenha sido excluida do Science Citation Index. Talvez devido à irregularidade da sua publicação. É uma situação que importa corrigir. De qualquer forma mantém-se o problema de atrair bons originais para a Revista. Isto exige uma atitude menos egoísta dos nossos químicos; e alguma imaginação para atrair bons artigos de autores estrangeiros.

\section{O Boletim da Sociedade Portuguesa de Química}

Nascido em Junho de 1977, com uma solução gráfica e de acabamentos a mais simples possível, manteve ainda a natureza artesanal até ao número 6 , publicado em Dezembro de 1978. Em Julho de 1979 saiu o primeiro número da II Série, agora já impresso em tipografia, mantendo-se como Director Ana Maria Lobo, que seria substituída no número 9, de Janeiro de 1982, por Virgílio Meira Soares. Este seria por sua vez substituído, a partir do n. ${ }^{\circ} 19$, de Março de 1985 , por Joaquim Moura Ramos, que ainda é o Director do n, 27 (II Série) que estão a ler, mas que também acha que é altura de ser substituído.

A história da publicação dos 33 números (incluindo os 6 números da I Série) do Boletim da SPQ é novamente a ilustração da dedicação e carolice de alguns, poucos, sócios da SPQ. Apesar dos seus altos e baixos o Boletim é a publicação da SPQ com maior impacto junto dos sócios e o excelente nível conseguido nos últimos números muito deve ao seu Director J. Moura Ramos. É absolutamente indispensável para a SPQ manter a publicação regular do Boletim, sem baixar a sua qualidade e mesmo, se possível, melhorando-a.

Para além da necessidade de encontrar um novo Directo que continue a excelente obra de Moura Ramos a principal dificuldade em relação à publicação regular do Boletim é, novamente, de ordem financeira. O preço de custo de cada número ronda os $130 \$ 00$ (fora os portes de correio), estão-se a publicar 4 números por ano, o Boletim é distribuido gratuitamente a todos os sócios, os subsídios são insuficientes e é difícil arranjar a quantidade de anúncios que idealmente tornariam o Boletim auto-suficiente em termos económicos. São dificuldades que têm de ser resolvidas. Tem de haver mais agressividade na angariação de subsídios e de anúncios; isto implica não só imaginação mas, principalmente, disponibilidade de tempo por parte do Director e dos seus colaboradores. E é preciso a ajuda de todos os sócios.

\section{Outras publicações}

Neste campo a actividade da SPQ tem sido, infelizmente, mais modesta. A região Centro (Divisão de Educação) publicou alguns textos didácticos e, a nível nacional, para além de um pequeno texto sobre equilibrio químico foram publicados os seguintes livros em colaboração com a Escolar Editora, de Lisboa: Química e Sociedade I (As Moléculas da Vida), Moura Ramos, Hernâni Maia e A.M. Lobo, Terminologia, Símbolo, e Unidades para Grandezas Fisico-Químicas, Maria Estela Jardim e Mariana Pereira e Estrutura Electrónica dos Átomos, Fernando Fernandes.

Outros títulos submetidos para publicação estão em fase de estudo.

As principais limitaçōes à actividade editorial da SPQ no que se refere à publicação de livros são, outra vez, de ordem financeira: a publicação de um livro exige um elevado investimento o qual leva, em geral, pelo menos dois a três anos para recuperar. Foi por isso que se iniciou a joint-venture com a Escolar Editora. Mas os editores também não estão interessados em ter o seu capital empatado durante muito tempo. A única solução seria a SPQ, sozinha ou em joint-venture, publicar alguns livros que fossem best sellers; de preferência livros para o ensino secundário que é a área em que o público é maior. Assim se criaria a folga necessária para poderem ser publicados também livros mais especializados que tivessem uma venda mais limitada. Infelizmente os nossos sócios que escrevem livros para o secundário preferem publicar os seus livros fora do âmbito da SPQ; talvez por compromissos anteriormente assumidos ou talvez, porque arranjem assim melhores retribuiçð̃es financeiras.

E existem também a Gulbenkian (felizmente, diga-se de passagem) que tem meios com os quais a $\mathrm{SPQ}$ não pode, evidentemente, concorrer.

Mas aqui fica o desafio: é preciso criar as condiçðes para que um autor sinta orgulho em ter um livro que foi seleccionado pela SPQ para publicação. Mais uma vez a criação destas condições exige imaginação, dedicação e tempo disponivel.

\section{O Prémio Ferreira da Silva}

Criado em 1980 o Prémio Ferreira da Silva foi anunciado e o seu regulamento descrito no Boletim n. ${ }^{\circ} 5$ (II Série) de Janeiro de 1981. Seria atribuído bienalmente ao químico português que, pelo trabalho produzido em Portugal no período de dois anos imediatamente anteriores ao da atribuição do prémio, mais tivesse contribuido para o avanço da Química em qualquer das suas áreas.

A primeira atribuição do Prémio foi em 1982 (Jorge C.G. Calado). Em 1984 houve duas candidaturas (António Xavier e Formosinho Sanches) e o júri decidiu atribuir dois prémios. Em 1986 não houve candidaturas apesar dos prazos da apresentação das mesmas terem sido alargados, o que foi noticiado no Boletim. 
Também no Boletim foram pedidas candidaturas para 1987 que, pelo que sei, também não apareceram. Não há interesse! $O$ que para mim é totalmente incompreensivel e revela a falta de maturidade na nossa comunidade científica. Ou a falta de prestígio da SPQ. Ou a total alienação que resulta do exagerado enfeudamento dos nossos químicos a grupos estrangeiros, o que os leva a não valorizarem nada que seja português (não se confunda esta crítica com qualquer sugestão de defesa de níveis de qualidade inferiores aos que são internacionalmente aceites). Ou então ninguém está interessado em avaliar e em comparar.

Aceito perfeitamente que o regulamento do Prémio talvez não fosse o melhor. Mas a Direcção estava aberta a considerar quaisquer propostas de modificação. Que também não apareceram.

A indiferença é que é inaceitável. Conduz necessariamente ao desgaste e põe em causa se vale a pena trabalhar para tal comunidade científica.

\section{O funcionamento geral da SPQ}

Apesar de todos os esforços realizados o funcionamento da Sociedade caracterizou-se por não termos conseguido quebrar o ciclo vicioso da pobreza. Como não há dinheiro para contratar pessoal a tempo inteiro (que inclua, pelo menos, um licenciado) não há capacidade de resposta nem capacidade organizativa que permitam lançar iniciativas que, eventualmente, trariam fundos para a Sociedade. As quotas pagas pelos sócios, mesmo depois do recente aumento, pouco mais cobrem que os custos do correio e não é possível subi-las mais sem correr o risco de se verificar uma quebra significativa no número de sócios. Frequentemente (mas não sempre) têm sido os lucros conseguidos nos Encontros que têm mantido a Sociedade.

A ausência de funcionários de nível adequado tem imposto aos sócios que trabalham para a Sociedade um esforço muito elevado; o que é agravado pelo facto de serem tão poucos. Aliás o nível global de participação dos sócios na vida da Sociedade (excluindo a comparência em Encontros) tem sido extremamente reduzida. Quase como anedota lembro uma Assembleia Geral para alteração dos Estatutos que funcionou com o Presidente da Mesa e com um membro na assistência que, por acaso, era o Secretário-Geral. Aliás a expressão que sempre considerei como mais irritante e que é frequentemente ouvida em reuniōes é: «a Sociedade deve fazer isto ou aquilo»; a Sociedade não é a Direcção, é o conjunto dos seus sócios e todos têm de colaborar! Sem uma máquina administrativa e sem maior participação dos sócios também nunca conseguiremos realizar outro dever da SPQ: ser não só uma sociedade científica mas, também, uma sociedade profissional (não confundir, claro, com sindical).

A ausência do tal funcionário qualificado e, principalmente, a debilidade económica também prejudicaram a interacção da SPQ com as suas congéneres a nível internacional. A SPQ continuou, durante todo este período, a estar filiada em algumas associaçð̄es estrangeiras como, por exemplo a IUPAC (o pagamento das quotas, mais ou menos atrasado, tem sido feito pelo Ministério dos Negócios Estrangeiros), a European Federation of Chemical Engineers e filiou-se em 1978 na FECS (Federation of European Chemical Societies). Com frequência recebemos solicitaçð̋es para participarmos em reuniðes e para nomearmos delegados para os vários grupos de trabalho. Mas só muito excepcionalmente há dinheiro para custear a ida de um dos nossos sócios a uma destas reunið̃es. Por vezes recebemos também pedidos de informações e de preenchimento de inquéritos por parte daquelas organizaçōes ou das nossas congéneres estrangeiras. Mas falta-nos o aparelho organizativo que permitiria a capacidade de resposta. É outro problema cuja resolução deixamos à capacidade dos vindouros.

Muito recentemente foi assinado um protocolo de colaboração entre a SPQ e a Sociedade de Quimica Brasileira e esta é outra área em que importa também investir algum esforço.

\section{O Secretário-Geral - passado, presente e futuro}

Poderá parecer estranho terminar estas notas com o apontamento sobre a figura do Secretário-Geral no funcionamento da SPQ. Considero, porém, que a experiência obtida $\mathrm{e}$ as responsabilidades que me cabem pelo exercício, durante nove anos, deste cargo justificam umas breves consideraçðes.

Do ponto de vista geral de funcionamento da SPQ tenho hoje a convicção de que a existência de um Presidente e de um Secretário-Geral, ambos exercendo as funçôes no seu tempo livre, não se justifica. Creio que futuramente o ideal seria ter um Secretário-Geral (licenciado ou mesmo doutorado) que fosse um funcionário a tempo inteiro da Sociedade e, então, o lugar de Presidente adquiriria muito mais significado. Não sei, porém, se será esta a opinião dos três Presidentes (Maria Alzira A. Ferreira, J.J.R. Fraústo da Silva e M.A.V. Ribeiro da Silva) com quem tive o privilégio de colaborar.

Do ponto de vista pessoal devo dizer que me deu muito prazer exercer as funçð̃es de Secretário-Geral. Procurei sempre pôr as minhas capacidades, muitas ou poucas, ao serviço da SPQ. Mas devo confessar que, progressivamente, o cansaço tem vindo a instalar-se. Não por falta de ideias ou de dedicação às causas que justificam a existência da SPQ e pelas quais ela deve lutar, mas pela constante falta de meios, de funcionários, e mesmo de colegas, indispensáveis para que a SPQ cumpra a sua missão.

Embora creia, sem falsas modéstias, ter contribuído um pouco para a revitalização e para a continuidade do funcionamento da SPQ, não tenho qualquer dúvida que, hoje em dia, a minha continuidade no cargo de Secretário-Geral é mais prejudicial do que benéfica para a Sociedade. E é justo que fique bem claro que sem o imenso esforço, dedicação e competência da Maria Cândida Vaz, actualmente Secretária-Geral Adjunta, o funcionamento da SPQ a nível de Direcção Nacional já teria paralisado há muito tempo.

Vamos eleger, entre outros membros directivos nacionais, um novo Secretário-Geral. Para além da sua credibilidade científica, de uma grande vontade e disponibilidade para trabalhar para a Sociedade ele tem também de ser um elemento conciliador e agregador da comunidade química portuguesa, É preciso ultrapassar eventuais conflitos regionais ou pessoais e evitar a desagregação da nossa comunidade através da criação de sociedadezinhas de qualquer-coisa-química ou de química-qualquer-coisa. Espero que apareçam bons candidatos e que saibamos escolher o melhor.

Termino agradecendo a todos os que comigo mais directamente colaboraram neste longo percurso, prestando a minha homenagem a todos os que de uma ou de outra forma contribuiram para manter a vida da SPQ, e saudando toda a comunidade química nacional. 

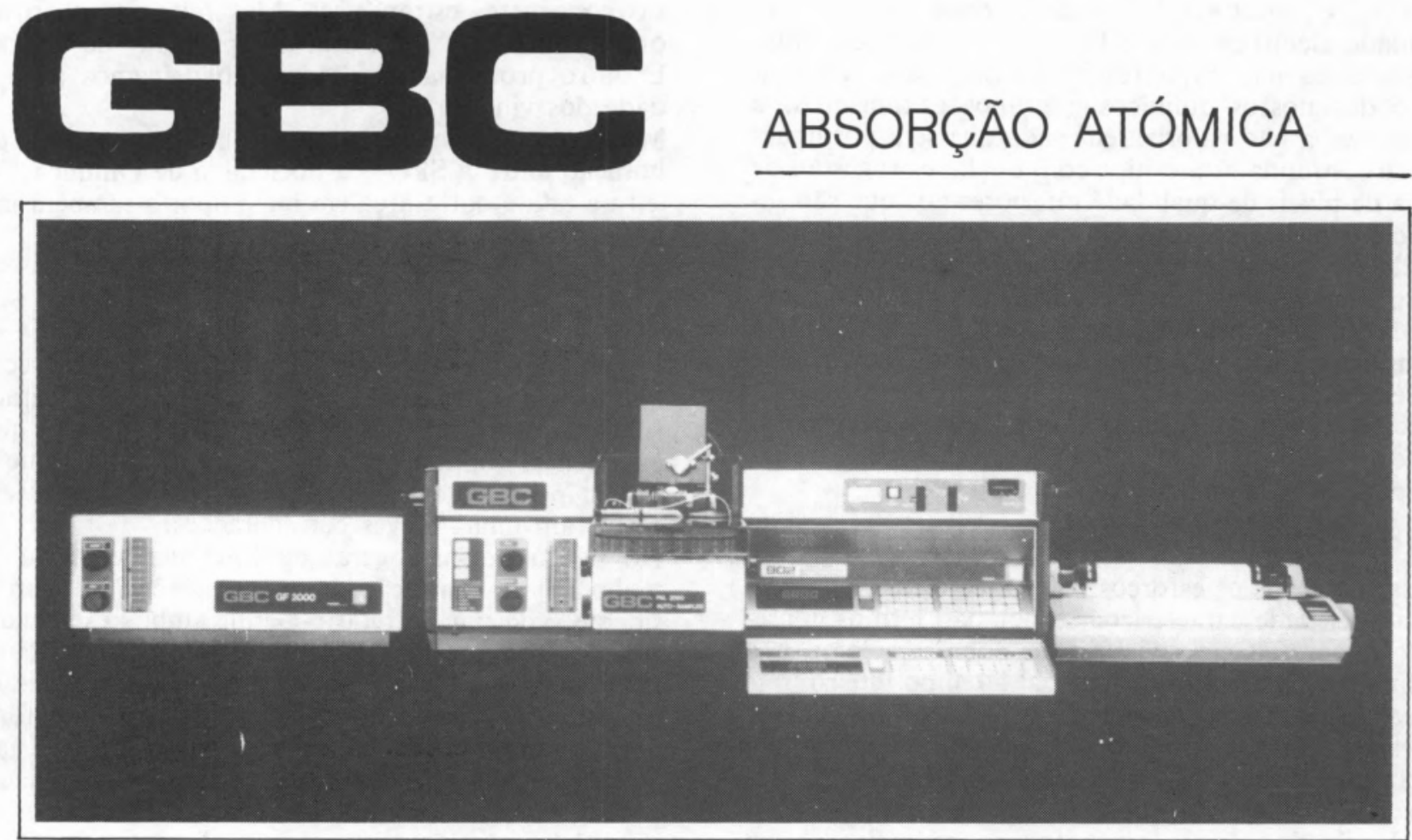

AGORA EM PORTUGAL

ABSORÇÃO ATÓMICA CHAMA-SE:
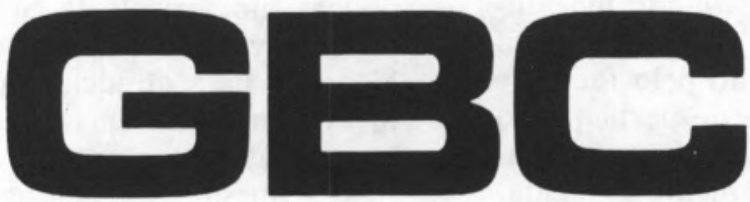

EXCELENTES EQUIPAMENTOS

AOS MELHORES PREÇOS DO MERCADO

(2 sistemas vendidos nos primeiros 3 meses de promoção)

PEÇA-NOS UMA OFERTA.

DISTRIBUIDORES EM PORTUGAL:

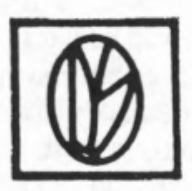

\section{ロ戸戸 エ曰}

QUINTA DA PIEDADE, LOTE $12.1 .^{\circ} \mathrm{D}$. 2625 PÓVOA DE STA. IRIA

TEL. (01) $2592316 \cdot 2592409$

TLX. 43926 DISO P

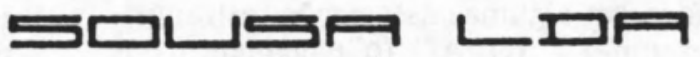

PRAÇA PEDRO NUNES, 94 4000 PORTO

TEL. (02) 931499 - 933809 TLX. 26250 NSC P 


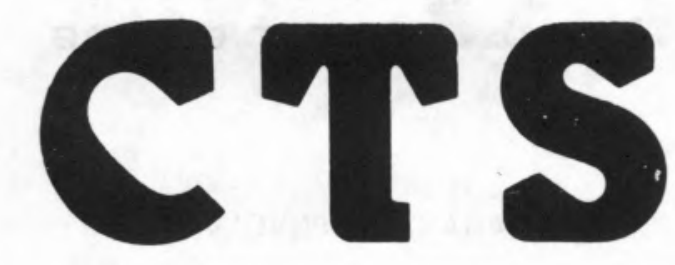

REVISTA DE

CIÊNCIA

JANEIRO 1987

N. ${ }^{\circ} 1$

TECNOLOGIA

E SDCIEDADE REVISTA quADRIMESTRAL

INDICE

\section{PROPRIEDADE DA:}

Associação de Ciência e Tecnologia para o

Desenvolvimento [ACTD]

MORADA: Av. Prof. Gama Pinto, 2

1699 Codex Lisboa

DIRECTOR: A. Romão Dias

EDITOR: M. Eduarda Gonçalves

CONBELHO REDACTORIAL:

Fernando Bello, Ana Luisa

Janeira, Filomena Mónica, J.

Moura Ramos

\section{CONBELHO CONBULTIVO:}

A. Trigo de Abreu, J. Ferreira de Almeida, M. Pinto Barbosa, M.

Villaverde Cabral, Jorge G.

Calado, João Caraça, João

Cravinho, Victor Crespo, L.

Veiga da Cunha, J. Dias de Deus.

J. Mariano Gago, Fernando Gil,

Jaime Reis, Mário Ruivo, J. J.

Salomon, Boaventura Sousa

Santos, J. J. R. Fraústo da' Silva,

Frederico Mayor Zaragoza

DEgENHADOR: Renato Abreu

DIBTRIBUIDOR: GRADIVA

\section{IMPREgBÃO:}

SANTELMO/Artes Gráficas

TIRAGEM: 3000 Exemplares

NÚMERO AVULBO: $300 \$ 00$

ABBINATURA:

750\$00 [3 números]

Depósito Legal n. ${ }^{\circ} 15386 / 87$

ISSN 0870 - 7642

\section{ENTIDADEB GUE}

BUBBIDIARAM A PUBLICAÇAO DEBTE NÚMERO

- Junta Nacional de Investigação Cientifica e Tecnológica [JNICT]

- Fundação Calouste Gulbenkian
EDITORIAL

\section{ARTIGOS}

- Ciência sem fronteiras, fronteiras sem ciência

$$
\text { 」. J. Salomon }
$$

- Ciência Tecnologia e Sociedade - uma perspectiva europeia, Arie Rip

- Inovação, Tecnologia e Mudança

Fernando Gonçalves e João Caraça

- Novas Tecnologias da Informação e Direito

$$
\text { M. Eduarda Gonçalves }
$$

- $\square$ caldeirão industrial, Jorge Calado

\section{NOTAS E DOCUMENTOS}

- A Ciência é para todos

- Necessidades em CAT para o desenvolvimento económico

- INICT - Ciência, Tecnologia e Sociedade

- Unidades de ensino e investigação em Ciência, Tecnologia e Sociedade

- JNICT - Inovação tecnológica e desenvolvimento regional

- 6. ${ }^{a}$ Conferência Pairlamentar e Cientifica do Conselho da Europa

- Declaração de Veneza - A Ciência e os limites do conhecimento

- Política de investigação cientifiça e tecnológica das Comunidades Europeias

LIVROS

- Ideas of Science

- International Science and the role of ICSU: a contemporary agenda

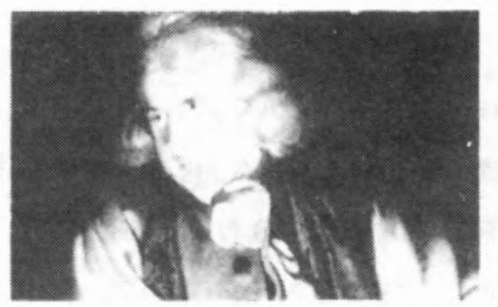

Um filósofo a dar uma lição sobre o planetário

Joseph Wright of Derby [1768] 


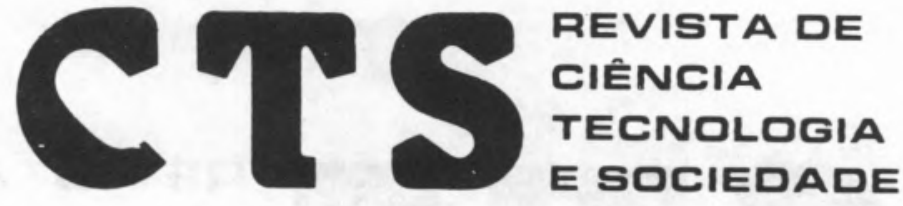

UMA PUBLICAÇÃO DA ACTD - ASSOCIAÇÃO DE CIÊNCIA E TECNOLOGIA PARA O DESENVOLVIMENTO

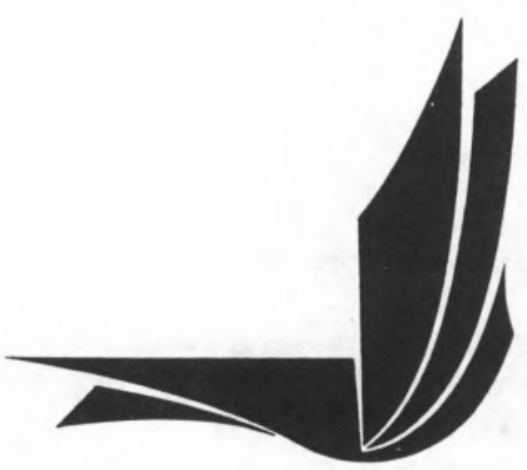

A ACTD é uma Associação sem fins lucrativos que tem por objectivo promover o estudo, a discussão e a divulgação da problemática e do progresso da ciência e tecnologia, em particular na perspectiva da sua aplicação para fins de desenvolvimento económico e social.

A CTS - Revista de Ciência, Tecnologia e Sociedade é uma publicação da ACTD. Visa criar um espaço de informação e de debate sobre a influência das condições sociais na criação da ciência e da tecnologia, as relações entre a ciência e a tecnologia, e o impacto destas na sociedade. E também, contribuir para a formulação de políticas científicas em Portugal. A perspectiva interdisciplinar, a estrutura e o nível equilibrado no tratamento dos temas tornam-na única no espectro editorial português. No verso desta página encontrará informação geral sobre a CTS e o índice do $1 .^{\circ}$ número. Esperamos que the agrade. Se já é sócio da ACTD receberá, como oferta, o $1 .^{\circ}$ número, quer faça ou não assinatura. A CTS foi feita para si. Assine-a e divulgue-a. A sobrevivêncıa deste projecto depende da sua viabilidade económica. Se anunciar na CTS ajuda-nos a manter a sua publicação. Contamos com todos e, muito especialmente, com os sócios da ACTD.

CORTE POR AQU

BOLETIM DE ASSINATURA DA CTS - REVISTA DE CIÊNCIA, TECNOLOGIA E SOCIEDADE

NOME

MORADA

LOCALIDADE CÓD. POSTAL

PROFISSÃO

LOCAL DE TRABALHO

ASSINATURA ANUAL (1987) - 3 NÚMEROS

SÓCIO DA ACTD $600 \$ 00$

NÃO SÓCIO DA ACTD $750 \$ 00$

CHEQUE N. ${ }^{\circ}$ BANCO

(Å ORDEM DE: ASSOCIAÇÃO DE CIÊNCIA E TECNOLOGIA PARA O DESENVOLVIMENTO)

DESEJO RECEBER OS ESTATUTOS DA ACTD E UMA FICHA DE INSCRIÇÃO

ESTOU INTERESSADO EM PUBLICAR UM ANÚNCIO NA CTS.

DESEJO RECEBER AS VOSSAS CONDIÇÕES DE PUBLICIDADE 